\title{
Removal of calcium hydroxide from Weine Type II systems using photon-induced photoacoustic streaming, passive ultrasonic, and needle irrigation: a microcomputed tomography study
}

\author{
Adam LLOYD'1, Geraldine NAVARRETE 1 , Melissa Andreia MARCHESAN'1, David CLEMENT² \\ 1- University of Tennessee Health Science Center, College of Dentistry, Department of Endodontics, Memphis, TN, USA. \\ 2- The University of Oklahoma, College of Dentistry, Oklahoma City, OK, USA.
}

Corresponding address: Adam Lloyd - University of Tennessee Health Science Center - College of Dentistry - Department of Endodontics - Union Ave. Memphis TN 38163 - United States - Phone: (901) 448-1731 - Fax: (901) 448-1799 - email: alloyd@uthsc.edu

Submitted: April 28, 2016 - Modification: July 13, 2016 - Accepted: August 1, 2016

\section{ABSTRACT}

\begin{abstract}
O bjective: This study compared the effectiveness of Er:YAG laser-activated irrigation (PIPS), passive ultrasonic irrigation (PUI) with EndoUltra and standard needle irrigation (SNI) in the removal of calcium hydroxide $\left[\mathrm{Ca}(\mathrm{OH})_{2}\right]$ from the mesial roots of Weine Type II mandibular molars. Material and Methods: Thirty mandibular molars were screened by $\mu C T$ for the presence of mesial roots with complex intra-canal anatomy and a common apical foramen. The teeth were enlarged to a standardized 25/.06 preparation and filled with $\mathrm{Ca}(\mathrm{OH})_{2}$ paste. Specimens were divided into three groups $(n=10)$ according to the technique used for $\mathrm{Ca}(\mathrm{OH})$, removal: PIPS, at $15 \mathrm{~Hz}$ and $20 \mathrm{~mJ}$ using a $9 \mathrm{~mm}$ long, $600 \mu \mathrm{m}$ diameter tip; PUI using a 15/.02 tip; and SNI (30 Ga. side-vented needle). Equal volumes of $8.25 \% \mathrm{NaOCl}$ and $17 \%$ EDTA were used in all groups. $\mu \mathrm{CT}$ was used to measure the initial amount of $\mathrm{Ca}(\mathrm{OH})_{2}$, present and to assess the residual volume of $\mathrm{Ca}(\mathrm{OH})_{2}$ following each irrigation protocol. Data were analyzed using Tukey HSD and Kruskal-Wallis tests $(\alpha=5 \%)$. Results: The mean volume of $\mathrm{Ca}(\mathrm{OH})_{2}$ before removal was significantly higher in the coronal third than in the middle and apical third $(p<0.001) . \mathrm{Ca}(\mathrm{OH})$, was similarly removed from the coronal and middle thirds with the three methods used $(p>0.05)$. PIPS (median 0\%; IQR: 0-0) showed significant higher $\mathrm{Ca}(\mathrm{OH})_{2}$ removal in the apical third than PUI (median 100\%, IQR: $85-100)$ and SNI (median 47\%; IQR: $16-72)(p<0.001)$. Conclusions: PIPS laser-activation was more effective for the removal of $\mathrm{Ca}(\mathrm{OH})_{2}$ from mesial roots of mandibular molars with Weine Type II canal configurations than PUI with EndoUltra and SNI.
\end{abstract}

Keywords: Endodontics. Lasers. Ultrasonics. Intracanal dressing. Irrigants.

\section{NTRODUCTI ON}

Intracanal medicaments have been used to further reduce the bacterial load of the root canal system that chemomechanical debridement may not remove ${ }^{20}$. Among these, calcium hydroxide $\left[\mathrm{Ca}(\mathrm{OH})_{2}\right]$ has been the most widely accepted intracanal medicament because of its high $\mathrm{pH}$ (12.5) and its ability to significantly reduce the bioburden and endodotoxin concentrations in teeth with apical periodontitis ${ }^{1,25}$. Concerns have been raised about the potential interactions of the remaining $\mathrm{Ca}(\mathrm{OH})_{2}$ and endodontic sealers. Margelos, et al. ${ }^{19}$ (1997) demonstrated incomplete setting and increased brittleness of zinc oxide-eugenol based sealers. Barbizam, et al. ${ }^{3}$ (2008) reported diminished adhesion of Epiphany sealer to root canal walls. Kim and $\mathrm{Kim}^{11}$ (2002) reported that the potential for $\mathrm{Ca}(\mathrm{OH})_{2}$ to dissolve in water could influence the long term leakage of root canal obturation. Hence, prior to obturation, intracanal medicaments must be removed from the root canal system to allow the penetration of root canal sealer into canal intricacies and dentinal tubules leading to a hermetic seal ${ }^{15}$. 
Different techniques have been proposed for the removal of $\mathrm{Ca}(\mathrm{OH})_{2}$ from the root canal system, including a combination of irrigating solutions and devices ${ }^{6,18,23}$. The most frequently described technique includes a combination of irrigation and recapitulation of the master apical file ${ }^{23}$. In this instance, only the $\mathrm{Ca}(\mathrm{OH})_{2}$ in the main canal will be disrupted with the file while persisting in system extensions or irregularities relying entirely on irrigation for the removal of $\mathrm{Ca}(\mathrm{OH})_{2}$ from these regions. While some investigators have shown a combination of ethylenediaminetetraacetic acid (EDTA) and sodium hypochlorite $(\mathrm{NaOCl})$ irrigants completely remove $\mathrm{Ca}(\mathrm{OH})_{2}$ from single systems ${ }^{6}$, others report that complete removal of medicaments from such teeth is unlikely ${ }^{7}$. Furthermore, they suggest depth of needle penetration plays a significant role in the removal process ${ }^{7}$.

The effectiveness of irrigation depends on the chemical action of the irrigant and the ability to bring the irrigant in contact with the complex structures within the root canal system ${ }^{22,26}$. Energizing irrigants with activated devices has been used to enhance fluid interchange when compared with needle irrigation. Passive ultrasonics have demonstrated enhanced irrigation through the creation of eddy currents and microstreaming along the instrument shaft and improved $\mathrm{Ca}(\mathrm{OH})_{2}$ removal2,18. A recent study evaluated the effect of the GentleWave system (Sonendo Inc, Laguna Hills, California, USA) in the removal of $\mathrm{Ca}(\mathrm{OH})_{2}$ from mandibular molars with two separate mesial canals ${ }^{18}$. The investigators found that this treatment was able to render mesial canals free of $\mathrm{Ca}(\mathrm{OH})_{2}$ when compared with passive ultrasonic irrigation (PUI) and standard needle irrigation (SNI). Although this system shows encouraging results, there are drawbacks to its clinical use, including the difficulty in attaching a customized disposable handpiece to individual teeth for stabilization creating a closed system for delivery of the multisonic stream of irrigants. Promising results for the removal of $\mathrm{Ca}(\mathrm{OH})_{2}$ have also been shown using an Erbium:YttriumAluminum-Garnet (Er:YAG) laser coupled with a short radial-stripped tip in a technique known as photon-induced photoacoustic streaming (PIPS; Fidelis; Fotona, Ljubljana, Slovenia). Arslan, et al. ${ }^{2}$ (2015) demonstrated that PIPS irrigation provided complete removal of $\mathrm{Ca}(\mathrm{OH})_{2}$ from artificial grooves in single-rooted teeth when compared with ultrasonic, sonic, and SNI techniques, which did not.

Multiple investigations have examined $\mathrm{Ca}(\mathrm{OH})_{2}$ removal from non-complex single-rooted teeth that may present misleading information not representative of the complex anatomy encountered by endodontists ${ }^{2,6,23}$. Recent microcomputed tomographic $(\mu \mathrm{CT})$ studies on the anatomical complexities of the mesial roots of mandibular molars have shown a prevalence of isthmuses of approximately $80 \%$ between $3-6 \mathrm{~mm}$ from the apex ${ }^{9,26}$. These anatomical structures can retain debris from instrumentation ${ }^{8,21}$; microbes $^{5}$; and $\mathrm{Ca}(\mathrm{OH})_{2}{ }^{17,18}$.

The use of $\mu \mathrm{CT}$ imaging to volumetrically assess the removal of $\mathrm{Ca}(\mathrm{OH})_{2}$ allows for a three dimensional quantitative evaluation based on gray values with higher sensitivity than sectioning techniques ${ }^{28}$. The purpose of this study was to use $\mu \mathrm{CT}$ imaging to assess the efficiency of PIPS laseractivated irrigation, a PUI with EndoUltra and SNI in the removal of $\mathrm{Ca}(\mathrm{OH})_{2}$ from the mesial roots of Weine Type II mandibular molars with complex anatomy.

\section{MATERIAL AND METHODS}

Tooth selection followed protocol approval from an Institutional Review Board with no patient health identifiers associated with the obtained samples (14-03540-XM). Mandibular molars were screened for the presence of isthmuses and Weine Type II canal configurations (two orifices - two canals one apical foramen) using a high-resolution $\mu C T$ scanning system (ACTIS BIR 150/130, Varian Medical Systems, Palo Alto, California, USA). The images were acquired at $75 \mathrm{kV}$ and $100 \mu \mathrm{A}$ through $360^{\circ}$ of rotation around the vertical axis resulting in a cross-sectional pixel size of approximately $30 \mu \mathrm{m}$. Each backscatter projection had a 16-bit addressable $1,024 \times 1,024$ area and was used to create a volume-rendered representation (VG Studio Max 2.3; Volume Graphics GmbH, Heidelberg, Germany). Thirty teeth were selected and the distal root of each sample was sectioned with a diamond disc just below the orifice and sealed with unfilled resin. Samples were individually mounted in a Teflon mold to allow precise positioning in a jig on the $\mu \mathrm{CT}$ stage.

All endodontic procedures were performed under the clinical microscope at $\times 14$ magnification (OPMI Pico, Carl Zeiss Meditec Inc., Jena, Germany) by a board-certified endodontist with 20 years of clinical experience. Canals were instrumented in a Crown-Down manner, briefly: \#6 down to \#3 Gates-Glidden drills (Dentsply Maillefer, Ballaigues, Switzerland), followed by $25 / .12$ and $25 / .10 \mathrm{~K} 3$ Orifice Openers (SybronEndo, Orange, California, USA), and by \#30/.06, 35/.04, and 25/.06 Profile Vortex (Dentsply Tulsa Dental Specialties, Tulsa, Oklahoma, USA) instruments. The apical preparation was standardized to a $25 / .06$ at $0.5 \mathrm{~mm}$ from the apical foramen and apical patency was verified with a \#10 K-file. Postinstrumentation irrigation was performed with alternating $8.25 \% \mathrm{NaOCl}$ (The Clorox Co, Oakland, California, USA) and 17\% EDTA (Roth Drug Co, Chicago, Illinois, USA) with PIPS 
laser-activated irrigation at a wavelength of 2,940 $\mathrm{nm}$ in $30 \mathrm{~s}$ exposure intervals at $15 \mathrm{~Hz}$ and $20 \mathrm{~mJ}$. A $9 \mathrm{~mm}$ long, $600 \mu \mathrm{m}$ diameter quartz tip, with the polyamide tip stripped back $3 \mathrm{~mm}$ was used. All samples were dried with sterile paper points and a premixed calcium hydroxide/barium sulfate paste (Ultracal XS, Ultradent Products Inc, South Jordan, Utah, USA) was injected into the mesial canals using a 30 Ga NaviTip (Ultradent). A Lentulo spiral filler (\#2, Miltex, York, Pa., USA) was used $1 \mathrm{~mm}$ short of the binding point in a slow-speed handpiece until $\mathrm{Ca}(\mathrm{OH})_{2}$ was visualized at the apical foramen ${ }^{27}$. A cotton pellet was placed on the floor of the pulp chamber and the access cavity was sealed (Cavit, 3M ESPE, Seefeld, Germany). A proximal radiograph was taken to confirm the intracanal $\mathrm{Ca}(\mathrm{OH})_{2}$ length and density. The apices of all specimens were sealed with sticky wax. The specimens were stored at $37^{\circ} \mathrm{C}$ in $100 \%$ humidity for seven days and a second $\mu \mathrm{CT}$ scan was performed to quantify the percentage volume of $\mathrm{Ca}(\mathrm{OH})_{2}$ occupying the root canal system.

The specimens were accessed again and a size 25 Flex-O-file (Dentsply Maillefer, Ballaigues, Switzerland) along with $3 \mathrm{~mL}$ of $\mathrm{NaOCl}$ was inserted into each canal for the working length to loosen the $\mathrm{Ca}(\mathrm{OH})_{2}{ }^{14,23}$. The specimens were then randomly distributed into three experimental groups $(n=10)$ :

\section{Group 1}

Laser-activated irrigation using an Er:YAG laser and a PIPS tip was performed according to the manufacturer's instructions. The tip was placed into the access cavity only and activated with each of the following irrigating solutions as they were introduced into the chamber with a 28 Ga sidevented irrigation needle:

Step 1: Three $30 \mathrm{~s}$ cycles of $6 \mathrm{~mL} /$ interval of $8.25 \% \mathrm{NaOCl}$ interrupted by a $30 \mathrm{~s}$ wait between each cycle

Step 2: 30 s cycle of $6 \mathrm{~mL}$ of water

Step 3: $30 \mathrm{~s}$ cycle of $6 \mathrm{~mL}$ of $17 \%$ EDTA

Step 4: $30 \mathrm{~s}$ cycle of $6 \mathrm{~mL}$ of water

\section{Group 2}

The PUI with EndoUltra protocol was the same as for PIPS following the steps previously described. However, PUI was delivered using nickel-titanium activator tips (15/.02) in a cordless ultrasonic handpiece (EndoUltra, Vista, Racine, Wisconsin, USA) and activated as far apically as achievable without binding in $2 \mathrm{~mm}$ amplitude motions.

\section{Group 3}

SNI was conducted with a 30 Ga side-vented needle delivering $18 \mathrm{~mL}$ of $8.25 \% \mathrm{NaOCl}$ over a period of $90 \mathrm{~s}$ at a distance of $2 \mathrm{~mm}$ close to the working length with $2 \mathrm{~mm}$ amplitude movements, followed by $6 \mathrm{~mL}$ of water, $6 \mathrm{~mL}$ of $17 \%$ EDTA delivered over $30 \mathrm{~s}$, and a final rinse of $6 \mathrm{~mL}$ of water.

The total volume of irrigation was the same in all experimental groups.

A final $\mu \mathrm{CT}$ scan was performed following irrigation. Three-dimensional (3D) volumes were automatically generated from thresholding and region growing based on grey values, separating $\mathrm{Ca}(\mathrm{OH})_{2}$ from dentin. The unchanged outer root surface of the second and final scans allowed precision alignment of both overlaid 3D datasets to subvoxel accuracy (VG Studio Max 2.3, Volume Graphics GmbH, Heidelberg, Germany). Total $\mathrm{Ca}(\mathrm{OH})_{2}$ volume from each specimen was derived from opaque (bright) voxels within the confines of the radiopaque canal walls. Each specimen was measured from apical foramen to orifice and equally divided into coronal, middle, and apical thirds. Regions of interest for each third were created based on slice position and volumes recorded.

The images were qualitatively evaluated in a double-blind manner by two independent precalibrated evaluators to classify the removal of $\mathrm{Ca}(\mathrm{OH})_{2}$ from the isthmus area. A four-level score system was employed:

$1=$ Clean isthmus, no $\mathrm{Ca}(\mathrm{OH})_{2}$.

$2=$ Clusters of $\mathrm{Ca}(\mathrm{OH})_{2}$ filling $\leq 50 \%$ of the volume.

$3=$ Clusters of $\mathrm{Ca}(\mathrm{OH})_{2}$ filling $>50 \%$ of the volume.

$4=$ Isthmus completely filled with $\mathrm{Ca}(\mathrm{OH})_{2}$.

The Shapiro-Wilk test was used to assess data normality. The mean volume of $\mathrm{Ca}(\mathrm{OH})_{2}$ per third before removal had a normal distribution and data were compared with one way-ANova and Tukey HSD tests. Kruskal-Wallis one way-ANova test was used to compare the mean percentage volume of $\mathrm{Ca}(\mathrm{OH})_{2}$ remaining after the different irrigation techniques. The specific pattern of differences between the interaction root canal thirds and irrigation techniques was demonstrated by Tukey's HSD pairwise tests. The level of significance was set at $a<0.05$. The Kappa coefficient was used to determine the interobserver reproducibility for the removal of $\mathrm{Ca}(\mathrm{OH})_{2}$ from the isthmus area. Statistical analysis was performed using SigmaPlot 13.0 (Systat, San Jose, California, USA).

\section{RESULTS}

The mean $\mathrm{Ca}(\mathrm{OH})_{2}$ volume before removal was $9.21 \pm 2.19,9.69 \pm 2.34$, and $10.83 \pm 2.50 \mathrm{~mm}^{3}$ for SNI, PIPS, and PUI respectively. The mean volume of $\mathrm{Ca}(\mathrm{OH})_{2}$ before removal was significantly higher in the coronal third than in the middle and apical third, and the middle was higher than the apical third $(p<0.001)$.

The volume of $\mathrm{Ca}(\mathrm{OH})_{2}$ remaining in the mesial 
roots of Weine Type II mandibular molars was significantly different for the studied irrigation techniques $(p<0.0001)$ (Figure 1$)$. PUI (median $8.33 \%$ ) and SNI (median $4.78 \%$ ) showed the highest amounts of remaining $\mathrm{Ca}(\mathrm{OH})_{2}$ when compared with PIPS (median $0.00 \%$ ), which showed the lowest $(p<0.01)$. None of the specimens in the PUI group were completely free of $\mathrm{Ca}(\mathrm{OH})_{2}$, with the apical third showing the highest percentage of remaining $\mathrm{Ca}(\mathrm{OH})_{2}$ (median $100 \%$ ). SNI

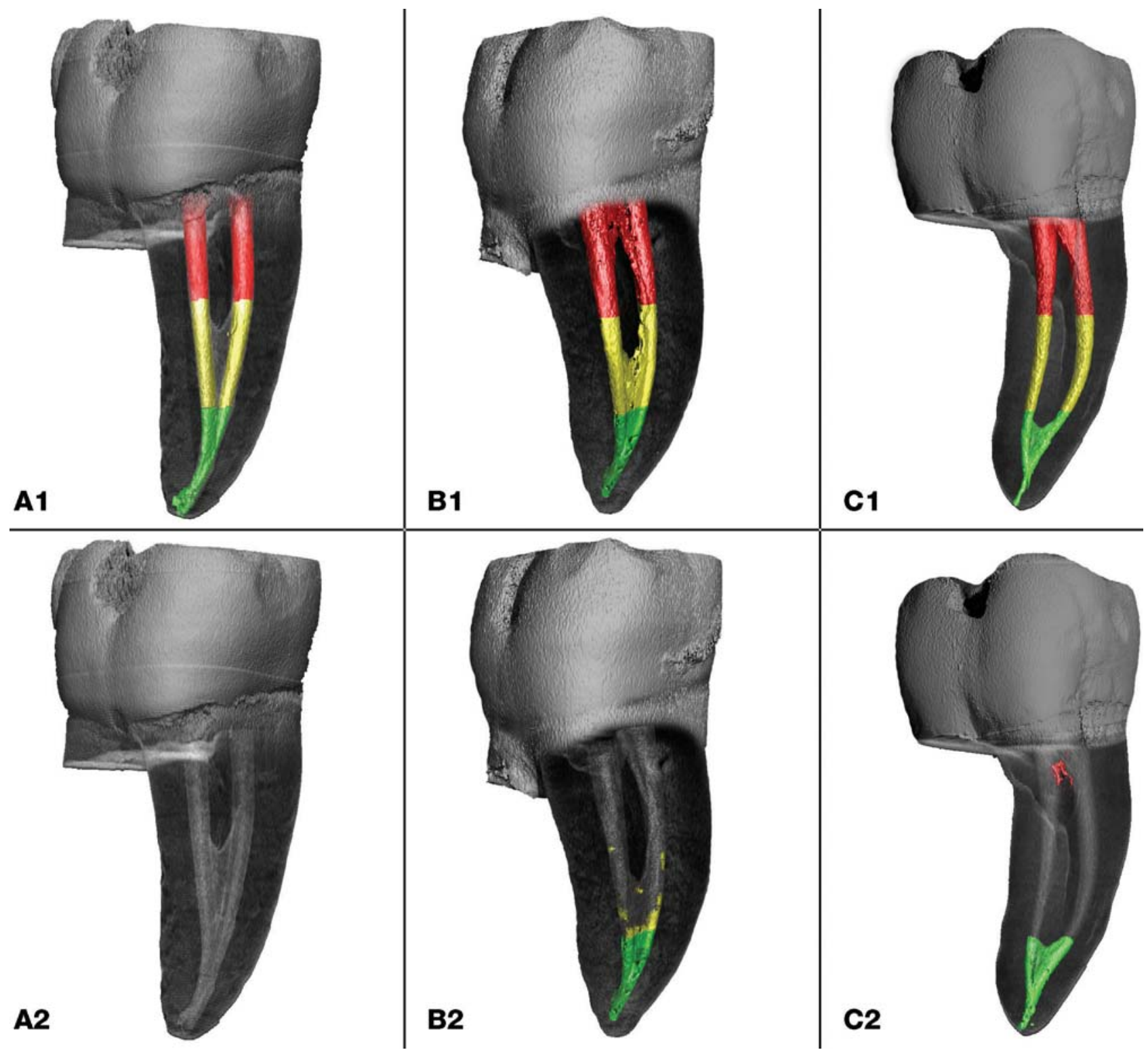

Figure 1- Three-dimensional reconstructions of mesial roots of mandibular molars with Weine Type II canal configurations illustrating remaining $\mathrm{Ca}(\mathrm{OH})_{2}$ in the different canal thirds (coronal - red; middle - yellow; apical - green) before (A1-C1) and after irrigation protocols (A2) PIPS, (B2) PUI, (C2) SNI.

Table 1- Median (interquartile range) percentage of remaining $\mathrm{Ca}(\mathrm{OH})_{2}$ after irrigation with different techniques for canal thirds

\begin{tabular}{cccc}
\hline & Coronal & Middle & Apical \\
\hline PIPS & $0 \%(0 \%, 0 \%)^{\mathrm{aA}}$ & $0 \%(0 \%, 0 \%)^{\mathrm{aA}}$ & $0 \%(0 \%, 0 \%)^{\mathrm{aA}}$ \\
PUI & $0 \%(0 \%, 0 \%)^{\mathrm{aA}}$ & $0.50 \%(0 \%, 5.82 \%)^{\mathrm{aA}}$ & $100 \%(85 \%, 100 \%)^{\mathrm{bB}}$ \\
SNI & $0.073 \%(0 \%, 0.416 \%)^{\mathrm{aA}}$ & $1.7 \%(0.8 \%, 4.5 \%)^{\mathrm{aA}}$ & $47 \%(16 \%, 72 \%)^{\mathrm{aB}}$ \\
\hline
\end{tabular}

Lowercase superscript letters indicate homogeneous subsets between canal thirds Uppercase superscript letters indicate homogeneous subsets between methods 
Table 2- Distribution of scores for the $\mathrm{Ca}(\mathrm{OH})_{2}$ removal from the isthmus area for different irrigation protocols

\begin{tabular}{ccccc}
\hline Groups & \multicolumn{3}{c}{ Scores for $\mathrm{Ca}(\mathrm{OH})_{2}$ removal from the isthmus area } \\
\hline & $\# 1$ & $\# 2$ & $\# 3$ & $\# 4$ \\
PIPS & 9 & 1 & 0 & 0 \\
PUI & 2 & 5 & 3 & 0 \\
SNI & 2 & 3 & 5 & 0 \\
\hline
\end{tabular}

showed a median of $47 \%$ of remaining $\mathrm{Ca}(\mathrm{OH})_{2}$ in the apical third and no differences between the thirds ( $p>0.05)$. PIPS showed a median of $0 \%$ of remaining $\mathrm{Ca}(\mathrm{OH})_{2}$ and no differences between the evaluated thirds $(p>0.05)$. The interaction between the irrigation methods and the root canal thirds showed that all irrigation methods used were statistically similar in removing $\mathrm{Ca}(\mathrm{OH})_{2}$ from the coronal and middle thirds (Table 1). However, PIPS showed statistically significant higher removal of $\mathrm{Ca}(\mathrm{OH})_{2}$ in the apical third when compared with both PUI and SNI $(p<0.001)$.

The interobserver Kappa coefficient was 0.89 for the removal of $\mathrm{Ca}(\mathrm{OH})_{2}$ from the isthmus area. A significant difference was found for PIPS $(p<0.05)$ when compared with SNI and PUI, which were statistically similar ( $p>0.05)$, whereas higher scores, which imply more $\mathrm{Ca}(\mathrm{OH})_{2}$ remaining in the isthmus area, were found for SNI and PUI (Table 2).

\section{DISCUSSION}

In the present study, all specimens were irrigated with PIPS prior to the placement of $\mathrm{Ca}(\mathrm{OH})_{2}$. PIPS has demonstrated the ability to remove debris from complex anatomy through high-velocity fluid interchange through expanding and collapsing cavitational bubbles along the root canal system ${ }^{12,16}$. ${ }^{s}$ A pilot study showed that PIPS irrigation allowed for better penetration of the intracanal medicament into isthmuses and interconnections between main canals for the type of teeth selected for this study.

This is the first qualitative investigation to examine remaining $\mathrm{Ca}(\mathrm{OH})_{2}$ in the isthmus area, which showed similar findings observed for the volumes of $\mathrm{Ca}(\mathrm{OH})_{2}$ in the different thirds. The highest amount of remaining $\mathrm{Ca}(\mathrm{OH})_{2}$ occurred with SNI and PUI. The rationale for such occurrence is the surface tension barrier created in the apical part of the canal that does not allow adequate flow into these complex non-separated areas ${ }^{18}$.

Irrigation with the recently marketed PUI device showed an overall $8.33 \%$ of $\mathrm{Ca}(\mathrm{OH})_{2}$ remaining in the root canal system, with no removal of medicament from the apical third. The isthmus area showed clusters of $\mathrm{Ca}(\mathrm{OH})_{2}$ filling less than $50 \%$ of the volume. We believe this is due to the inability of the EndoUltra tip to reach beyond the buccal-lingual curvature in spite of the 25/.06 apical enlargement.
The tips of the EndoUltra activator are a smooth $15 / .02$ wire, claimed by the manufacturer to be constructed from nickel-titanium. Manufacturer's instructions recommend tip placement at $2 \mathrm{~mm}$ from the canal terminus. In our study, the tip was placed in the canal as far apically as achievable without binding to move freely and improve the irrigant flow dynamics in the apical third of the root canal system ${ }^{13}$. This is the first investigation of the effectiveness of EndoUltra as an adjunct to irrigation in the literature. EndoUltra did not appear to have sufficient energy to generate the acoustic streaming and hydrodynamic shear stress propagation to eliminate $\mathrm{Ca}(\mathrm{OH})_{2}$ from the apical third. This is in contrast to other PUI with EndoUltra irrigation devices that have shown more effective removal of $\mathrm{Ca}(\mathrm{OH})_{2}$ when compared with $\mathrm{SNI}^{18,24}$.

For the SNI group, the tip of the needle was placed at a distance $2 \mathrm{~mm}$ close to the working length without binding. A $30 \mathrm{Ga}$ needle has an external diameter of $0.31 \mathrm{~mm}$, which is equivalent to the dimensions of a canal prepared to a 25/.06 at $1.0 \mathrm{~mm}$ less than the working length. Fluid dynamics in such circumstances only allows fluid interchange $0.75 \mathrm{~mm}$ from the tip of the needle ${ }^{4}$ and explains the resulting $47 \%$ of $\mathrm{Ca}(\mathrm{OH})_{2}$ remaining in the apical third.

Unlike SNI and PUI, the PIPS tip remains in the access cavity providing, expanding, and collapsing cavitational bubbles that progress as shear forces along the canal walls ${ }^{12}$. Our results showed no remaining $\mathrm{Ca}(\mathrm{OH})_{2}$ throughout the root canal system in mesial roots of mandibular molars with Weine Type II canal anatomy and isthmuses. Even the most apical area of the root canal, which normally imposes increased irrigation difficulties ${ }^{10}$, was free of $\mathrm{Ca}(\mathrm{OH})_{2}$. The increased average fluid velocity from the middle to apical third may have contributed to these results ${ }^{12}$. Additionally, samples tested were Weine Type II canal systems that allow fluid interchange to occur in a circular pattern between the mesio-buccal and mesio-lingual canals. The enhanced fluid movement and high velocity shear stresses could have resulted from the inherent canal anatomy, potentiating $\mathrm{Ca}(\mathrm{OH})_{2}$ removal from the apical third.

Under the conditions of the present study, the use of PIPS laser-activated irrigation demonstrated consistent removal of $\mathrm{Ca}(\mathrm{OH})_{2}$ from the entire canal 
system of mandibular molars with Weine Type II canal configurations, including the most complex isthmus areas found in the apical half. The new PUI and SNI did not consistently remove $\mathrm{Ca}(\mathrm{OH})_{2}$ from the canal system. The efficacy of PIPS irrigation in removing $\mathrm{Ca}(\mathrm{OH})_{2}$ from mandibular molars with different canal configurations should be investigated in future studies.

\section{CONCLUSI ONS}

Within the limitations of this study, our findings suggest that PIPS laser-activation was more effective for the removal of $\mathrm{Ca}(\mathrm{OH})_{2}$ from mesial roots of mandibular molars with Weine Type II canal configurations than PUI with EndoUltra and SNI.

\section{ACKNOWLEDGEMENTS}

We are grateful for the assistance and expertise provided by Dr. Daniela Handl, Volume Graphics $\mathrm{GmbH}$, in the evaluation of the 3D datasets. This study was supported by a resident research grant from AAE Foundation - American Association of Endodontists Foundation and is submitted in partial fulfillment of the requirements for the degree of Master of Dental Science.

\section{REFERENCES}

1- Adl A, Motamedifar M, Shams MS, Mirzaie A. Clinical investigation of the effect of calcium hydroxide intracanal dressing on bacterial lipopolysaccharide reduction from infected root canals. Aust Endod J. 2015;41:12-6.

2- Arslan H, Akcay M, Capar ID, Saygili G, Gok T, Ertas H. An in vitro comparison of irrigation using photon-initiated photoacoustic streaming, ultrasonic, sonic and needle techniques in removing calcium hydroxide. Int Endod J. 2015;48:246-51.

3- Barbizam JV, Trope M, Teixeira EC, Tanomaru-Filho M, Teixeira FB. Effect of calcium hydroxide intracanal dressing on the bond strength of a resin-based endodontic sealer. Braz Dent J. 2008;19:224-7.

4- Boutsioukis C, Gogos C, Verhaagen B, Versluis M, Kastrinakis E, Van der Sluis LWM. The effect of apical preparation size on irrigant flow in root canals evaluated using an unsteady Computational Fluid Dynamics model. Int Endod J. 2010;43:874-81.

5- Byström A, Claesson R, Sundqvist G. The antibacterial effect of camphorated paramonochlorophenol, camphorated phenol and calcium hydroxide in the treatment of infected root canals. Endod Dent Traumatol. 1985;1:170-5.

6- Calt S, Serper A. Dentinal tubule penetration of root canal sealers after root canal dressing with calcium hydroxide. J Endod. 1999;25:431-3.

7- Chou K, George R, Walsh LJ. Effectiveness of different intracanal irrigation techniques in removing intracanal paste medicaments. Aust Endod J. 2014;40:21-5.

8- Endal U, Shen Y, Knut A, Gao Y, Haapasalo M. A high-resolution computed tomographic study of changes in root canal isthmus area by instrumentation and root filling. J Endod. 2011;37:223-7. 9- Gu LS, Wei X, Ling JQ, Huang XY. A microcomputed tomographic study of canal isthmuses in the mesial root of mandibular first molars in a Chinese population. J Endod. 2009;35:353-6.
10- Kenee DM, Allemang JD, Johnson JD, Hellstein J, Nichol BK. A quantitative assessment of efficacy of various calcium hydroxide removal techniques. J Endod. 2006;32:563-5.

11- Kim SK, Kim YO. Influence of calcium hydroxide intracanal medication on apical seal. Int Endod J. 2002;35:623-8.

12- Koch JD, Jaramillo DE, DiVito E, Peters OA. Irrigant flow during photon-induced photoacoustic streaming (PIPS) using Particle Image Velocimetry (PIV). Clin Oral Investig. 2015;20:381-6.

13- Krell KV, Johnson RJ, Madison S. Irrigation patterns during ultrasonic canal instrumentation. Part I. K-type files. J Endod. $1988 ; 14: 65-8$.

14- Lambrianidis T, Kosti E, Boutsioukis C, Mazinis M. Removal efficacy of various calcium hydroxide/chlorhexidine medicaments from the root canal. Int Endod J. 2006;39:55-61.

15- Lambrianidis T, Margelos J, Beltes P. Removal efficiency of calcium hydroxide dressing from the root canal. J Endod. $1999 ; 25: 85-8$

16- Lloyd A, Uhles JP, Clement DJ, Garcia-Godoy F. Elimination of intracanal tissue and debris through a novel laser-activated system assessed using high-resolution micro-computed tomography: a pilot study. J Endod. 2014;40:584-7.

17- Ma J, Shen Y, Yang Y, Gao Y, Wan P, Gan Y, et al. In vitro study of calcium hydroxide removal from mandibular molar root canals. J Endod. 2015;41:553-8.

18- Ma JZ, Shen Y, Al-Ashaw AJ, Khaleel HY, Yang Y, Wang ZJ, et al. Micro-computed tomography evaluation of the removal of calcium hydroxide medicament from C-shaped root canals of mandibular second molars. Int Endod J. 2015;48:333-41.

19- Margelos J, Eliades G, Verdelis C, Palaghias G. Interaction of calcium hydroxide with zinc oxide-eugenol type sealers: a potential clinical problem. J Endod. 1997;23:43-8.

20- Nair PN, Henry S, Cano V, Vera J. Microbial status of apical root canal system of human mandibular first molars with primary apical periodontitis after "one-visit" endodontic treatment. Oral Surg Oral Med Oral Pathol Oral Radiol Endod. 2005;99:231-52. 21- Paqué F, Al-Jadaa A, Kfir A. Hard-tissue debris accumulation created by conventional rotary versus self-adjusting file instrumentation in mesial root canal systems of mandibular molars. Int Endod J. 2012;45:413-8.

22- Rosenfeld EF, James GA, Burch BS. Vital pulp tissue response to sodium hypochlorite. J Endod. 1978;4:140-6.

23- Salgado RJ, Moura-Netto C, Yamazaki AK, Cardoso LN, Moura AA, Prokopowitsch I. Comparison of different irrigants on calcium hydroxide medication removal: microscopic cleanliness evaluation. Oral Surg Oral Med Oral Pathol Oral Radiol Endod. 2009;107:580-4.

24- Silva LJ, Pessoa OF, Teixeira MB, Gouveia $\mathrm{CH}$, Braga RR. Micro-CT evaluation of calcium hydroxide removal through passive ultrasonic irrigation associated with or without an additional instrument. Int Endod J. 2015;48:768-73.

25- Sjögren U, Figdor D, Spångberg L, Sundqvist G. The antimicrobial effect of calcium hydroxide as a short-term intracanal dressing. Int Endod J. 1991;24:119-25.

26- Teixeira FB, Sano CL, Gomes BP, Zaia AA, Ferraz CC, SouzaFilho FJ. A preliminary in vitro study of the incidence and position of the root canal isthmus in maxillary and mandibular first molars. Int Endod J. 2003;36:276-80.

27- Torres CP, Apicella MJ, Yancich PP, Parker MH. Intracanal placement of calcium hydroxide: a comparison of techniques, revisited. J Endod. 2004;30:225-7.

28- Wiseman A, Cox TC, Paranjpe A, Flake NM, Cohenca N, Johnson JD. Efficacy of sonic and ultrasonic activation for removal of calcium hydroxide from mesial canals of mandibular molars: a microtomographic study. J Endod. 2011;37:235-8. 